\title{
Sing a Folk Song to You-Literature Research of Dabie Mountain Folk
}

\author{
Songs \\ Xiaoyu $\operatorname{Pan}^{1}$ \\ ${ }^{1}$ Yunnan Normal University, Kunming, Yunan, 650500 \\ 346591653@163.com
}

KEYWORDS: Dabie Mountain Folk Songs; Cultural Connotation; Artistic Characteristics; Social Value

\begin{abstract}
Dabie Mountain folk songs have high artistic charm and research value, the content is mainly five to seven words, red revolutionary songs and ballads based, diverse art practices, in $\mathrm{Fu}$, Xing, and other traditional techniques in the same time, the use of exaggeration and lining word and other techniques to enhance the effect of expression, singing form and structural features are also very flexible. Dabie Mountain folk heritage and through constant evolution, not only has a profound literary value, but also has a very important social value, worthy of our exploration and research.
\end{abstract}

\section{Introduction}

Towering Dabie Mountains across the three provinces, where the pines stand, stoning wear air, Kevin Flying, many have no risk magnificent place; beautiful, Swallows Ying Sheng, clear sky, more intoxicating spirits of the King. This vibrant piece of land eventually gave birth to a large number of good will, building heroes alone there since the Han Dynasty literature open new wind generation of education Wen Weng, the Northern Song Dynasty historian Sima Guang, the Southern Song Dynasty poet Lu this, the Ming Dynasty writer He Jingming. Mountain area of old times, countless heroes bow in homage, Jiji Mystics fight brush. Industrious villagers living yard, spring planting autumn harvest, winter provisions Xia Geng, sunrise, sunset, forming a unique local customs, gave birth to a beautiful wonderful work of art --- Dabie Mountain folk songs.

In 1924, the famous local writer Mr. Tai Jingnong came back to his hometown from Beijing University Lu'an leaf collection, collected more than two thousand folk ballads, in which more than 600 love songs will be handed over to the North Ballad and often Mr. Hui editor of the "Ballads Weekly" published 113. Later, Mr. Tai Jingnong in Taiwan published "Huainan folk collection", a collection of 113 songs and this other seven articles, which embarked on humble folk Dabie illustration. Dabie Mountain area was established in 1930, Henan, Anhui Revolutionary Base, enormous changes make people's thoughts and feelings and mental outlook has undergone tremendous changes, farmers impassioned folk form to record the revolutionary struggle, these revolutionary songs big quantity, quality high, very broad and deep reflection of life. After the founding of New China, the people's sovereignty, the creation of folk songs appeared in more prosperity, poet and folk songs of farmers in large numbers, performances have gradually diversified, such as when the new Anji Town, Lu'an farmers compose play "family", spread the north and south. During this period, folk creation and dissemination activities in other parts of the 
Dabie Mountain area has developed rapidly, such as Huanggang, Anqing Xinyang and other regions.

\section{Folk Cultural Connotation of the Dabie Mountains}

\section{A. Five Sentences of Seven Words Songs}

Dabie Mountain area of five words a long history with Seven songs, folk songs, also known as Seven - five words five sentences folk songs, as the name suggests is a Seven - five words as the basic format is one particular style of traditional folk songs in. Seven - five words in the formula accounts for the most number of Dabie Mountain folk songs, including all aspects of social life, which is love songs accounted for the largest proportion. Whether in mountain or town, you can hear the song everywhere. Love is the eternal theme of literature, folk songs is no exception. Songs are soul sparks video, stare flow wave is cured, it can often reflect one of the most instinctive, most sincere and most primitive thoughts and feelings. Si Love Story songs can be divided into the Dabie Mountains, praise songs, songs spouse, Lang sent the song and songs, the situation changed, they are true feelings, authentic love between men and women recorded Wyatt, long for, praise, chasing, and other emotional entanglements farewell, but also the times and social portrait, affectionate, beautiful and simple, the content is also very wide, can be summarized in the following three points:

Folk concept of love is very simple, people in pursuit of farming men and women weave, pure natural love, which is also reflected in folk songs. For example Jinzhai Min Song "Lang singing folk songs in the high mountains," singing: "Lang singing folk songs in the high mountains, little angel woven silk and sister in the room, hearing folk songs move the heart, neck and hand out a soft comb, non-woven rungra listen folk Songs. "this is the first widely circulated in the Dabie Mountain area to the west of Jinzhai County folk as folk tunes, clever demonstration of young men and women love each other emotional psychology. It is a hearty sing on the mountain and a fine woven silk and boudoir. I do not know the naughty Lang mountain pass into a little angel singing Xiufang sister, or sister being listened to that little angel heart singing. Anyway, singing through the natural boundaries, crossed the boundaries of the mind. "Comb out" the close-up, the "carried away" little angel sister image capture precise place. Finally, the little angel sister simply "non-woven silk and listen to folk songs," whether there Tingtingge own hopes. The spread in the Dabie Mountain area folk songs, simple expression of the people's yearning for a better love.

Jinzhai County is part of the hinterland of the Dabie Mountains, in the past where the natural environment is relatively closed and backward economy, living at the bottom of farmers devastated by the feudal oppression, natural disasters, life is extremely poor and miserable, so folk song there are a lot of minor affliction, particularly the plight of women in song, in form and content have some representation. In feudal times, women are subject to a variety of ethical code, there is no freedom of marriage, men and women unequal status, pulp married marriage, child brides, widows remarry, patriarchal marriage, which are not fair marriages are very common, so that women who have been great harm, Jinzhai county there is such a song: "look good sister to wear body blue, light does not wear turquoise dress, I want to dress up the pro-husband speaking, I do not dress outsiders talk about anti posted goalkeeper difficult." the performance of the old society by the oppression of women, for the wonderful things can not have a strong pursuit. Especially in marriage, such as Bitter Love Songs "Ten Hate" sings: "A slave hate father and mother, no father and mother argued that men and women being quite small, Why do not you hate to play two slaves dowry laws, good laws error? M size women Taisho consistency, Why do not to marry me? three hate matchmaking, matchmaking die, male female Taisho appropriate size, the marriage Why do not mention ...... 
"direct daring pain above her unfortunate love, anger but unable against despair, it sounds tearjerker.

\section{B. Red Revolution Songs}

Art is a reflection of the times and society, the era of the revolution will inevitably produce revolutionary songs. Dabie Mountain is a famous old revolutionary base areas, the cradle of the Red Army. In this piece of red land, mountains and plains of Dabie Mountain folk songs like red rhododendron, inspire people to break bloody. It is bathed in fire smoke, in the battle difficult birth; soak into the blood and tears of the people, get to use in the war, it is the people's revolutionary struggle of the magnificent red pictures, heroic epic, to be remembered in our hearts, in our flowing blood vessels, we should always treasure the world for generations. Dabie Mountain revolutionary songs on the content are as follows:

In the performance of passionate revolutionary war at the same time, there are some songs exposed the atrocities of the Kuomintang reactionaries. Such as "insult Jiang Fei", "a curse Chiang Kai-shek, the National Orders under attack three provinces, the Red Army encirclement I; two accused Jiang Fei forces, local tyrants and evil gentry collusion, the Red Army bloody killing me, means to endure so sad ......" These songs show different aspects of the environment was harsh times.

Red Army soldiers and civilians unite the ballad singing fish water conditions, such as "Code Red double sandals send" sings:. "Mountain pine root root, people love the Soviet Red Army, a diameter of four sides sandals, sandals double knitting send to the Red Army to wear sandals, followed step by step Mao members, frontline enemy to be brave and defend our three provinces. "in plain simple language to express the people's love for the Red Army, the Red Army painted a caring, kind and picture support for the Red Army. These immortal revolutionary songs are classic red and are the revolutionary struggles of mountain people to witness history, it has widely sung.

\section{Artistic Features of Folk Songs Dabie Mountains}

\section{A. Rich of Expression}

Dabie Mountain Ballads in rhetoric adopted since "Book of Songs" way than traditional national Fu Xing, while the use of a large number of metaphors and hyperbole deepened the effect of expression. Fu called "straight Syria" row being to apply directly to say, mind how to think, how to say the mouth. Which abound in the narrative ballad. Such as "I separated with a wall brother, he came to attend a lecture to eat. Eat shrimp Ma left legs, eat eggs leave yellow. I hurt people hurt wife Lang." This is the first in the United States and the feelings of plain folk, Fu naturally into articles, and its wonderful contented. Endowed with a lot of folk narrative detail, its purpose is to lyrical. After careful selection, refining and summarized the oral presentation of those difficult situation and things, with full character and action-oriented description language, and become the distinctive characteristics Dabie Mountain area Ballads.

Ratio, also known as "metaphor" or "comparable" to the people than was, people were blending. Dabie Mountain folk metaphor "category Fan" and "cut to" Ariake than darker than, parallelism, contrast and other types. That is a different thing than the Ming simile, metaphor body and body simultaneously, through the "like", "as", "like" and other words will be linked with common characteristics. Such as: "Down to wear like Yan Liu, Ying downhill race that fly" through the mountains compared to Liu Yan, down beat Orioles fly. By ratio, also known as metaphor, it is more artistic, eclipsing such as "double eaves dripping tears, eat light BU long fat," the entire sentence without a word of love, yet the extent of men and women miss performance thoroughly. 


\section{B. Unique Structural Features}

Folk musical structure having diverse characteristics, which constitute the main reason for this diversity are the two flexible structure diverse lyrics, second is the use of the word lining. Dabie Mountain Folk musical structure mostly short, the most common was a structure. Lyrics structure is the most representative body of Seven-five words folk songs, folk song for the five words, each sentence has seven words, dotting the last sentence of the sentence, also the center of the entire first sentence of folk songs. Such as: "The young girl students have behaved well behaved, well see her walking like a butterfly drifting dance, umbrella like Vita many people love good or bad..!" The first four sentences of the young girl walking likened butterfly dance, umbrella likened Vita, a vivid manifestation of cute beautiful young girl, the last sentence "How many good people love bad" more prominent beautiful young girl scene. Jinzhai poet $\mathrm{Xu}$ Yong had five words explain the function of specific body: "It is mainly used to describe first four sentences, bedding, rendering, fifth sentence is the last sentence is used to highlight the theme ......" Another example Jinzhai Songs: "eat the peach trees planted; eat fish the net lift; eat the rice fields species; eat fine flour mill to suffer; everything from work to."

Folk Songs lining the word no exact meaning, only to render the atmosphere or enhancing the songs colloquial and popularized in songs like foil position, so called liner word. It is not bound lyrics, can enjoy express emotion, lining word use is one of the distinguishing characteristics of the Dabie Mountains Folk Songs. In content, it helps to enrich the connotation of the song, the image of the rich music; in the form, you can make more sense of rhythm songs, breaking the form of restrictions to avoid telling a tale boring; structurally, some lining use of the word having a connection and a connecting role, such as "sedan chair to the front" in the "you", "I" is the connecting role; the "weaving rungra" in "call it babbling Hi ho" there is a connecting role. There are also songs of the singer in order to enhance the performance and appeal, in the middle or at the end of the lyrics word plus lining. Such as "I love and a brother embankment (le), stringers phase take (are) connected to the house. I have people say (Le) with good brother (hello), I actually (was) to take detached. (Hey brother), I take the body to eat mutton lamb mess.

\section{Conclusion}

Dabie relative isolation with the outside world, to a certain extent, to avoid infiltration and pollution complicated art, art created with a strong "vulgar" gas, such "vulgar" is the most valuable "mountain" flavor and "love" tune. Dabie Mountain Folk Although historic, the content is extremely rich, but after thousands of years of heritage and development, still always separated "mountain" flavor and "feeling" stressed that turns out to be "no mountain water is not a river, no sister, no fragmentation Lang song". Jinzhai mountain since ancient times "books make up the true folk opera," saying the song explains what is "true", the situation is "true", but it reflects the real folk customs more vivid. Dabie Mountain folk literary value is reflected in the character of the development of traditional folk songs, whether individual, collective or folk content under a macro perspective, it will develop the traditional connotation of the Dabie Mountain area to the extreme, thus extending a more extensive and profound Social value. Literary Value of Dabie Mountain Folk Songs not only important theoretical research, conservation practice and development of intangible cultural heritage are also important value.

\section{REFERENCE:}


[1] Tai Jingnong. The Original Folk Legend [M], Tai Jingnong Huainan Folk Songs. Taiwan: Oriental Culture Publishing House, 1970.

[2] Guan Yawei. Lu'an Dabie Mountain Folk Yawei Selection and Appreciation [M]. Beijing: China Culture Publishing House, 2010.

[3] Xu Yuanhua. Lu'an Ballads [M]. Beijing: China Federation of Literature Publishing House, 2011.

[4] Zhao Rong. Anthropogeography [M]. Beijing: Higher Education Press, 2006.

[5] Zhang Zhengming. Chu Cultural History [M]. Shanghai: Shanghai People's Publishing House, 1987. 